\section{CRITICAL MEDICAL AND SURGICAL NURSING JOURNAL \\ Vol. 10, No. 2, October 2021}

Journal Homepage: https://e-journal.unair.ac.id/CMSNJ

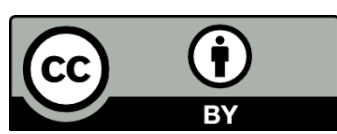

This is an Open Access article distributed under the terms of the Creative Commons Attribution 4.0 International License

\title{
Optimization of Self Monitoring Blood Glucose in Diabetes Mellitus Patients in Detecting Hypoglicemia Episodes: Literature Review
}

\author{
Ceria Nurhayati $(\mathbb{D}$ and Ninik Ambar Sari $(\mathbb{C}$ \\ STIKES Hang Tuah Surabaya, Surabaya, Indonesia
}

\author{
ARTICLE HISTORY \\ Received: October 31, 2021 \\ Accepted: December 10, 2021 \\ Published: December 10, 2021

\section{KEYWORDS} \\ self-monitoring blood glucose, \\ hypoglycemia, and diabetes \\ mellitus

\section{CORRESPONDING AUTHOR Ninik Ambar Sari niniksari040119@gmail.com STIKES Hang Tuah Surabaya, Surabaya, Indonesia}

\begin{abstract}
Introduction: Diabetes mellitus is a chronic disease that continues to increase yearly. The act of detecting hypoglycemic episodes is a must for a diabetic patient. This study aims to present the optimization of blood glucose self-monitoring measures in patients with diabetes mellitus and to review some of the literature on this topic.

Methods: This study is a form of literature review of articles with the theme Optimization SelfMonitoring Blood Glucose in diabetes mellitus patients detecting hypoglycemia episodes. Articles in this study came from the electronic databases of Google Scholar, PubMed, ProQuest, Scopus, and Science Direct from 2005 to 2020.

Result: Search results using the keywords Self-Management Blood Glucose, Hypoglycemia, Diabetes Mellitus were obtained from 57 articles. Eighteen articles that met the inclusion criteria were then reviewed for their full text.

Conclusion: Self-monitoring blood glucose is a preventive measure for detecting hypoglycemic episodes. This intervention is the best choice for patients to prevent further complications.

Nurhayati, C., \& Sari, N. A. (2021). Optimization of Self Monitoring Blood Glucose in Diabetes Mellitus Patients in Detecting Hypoglicemia Episodes: Literature Review. Crit. Méd. Surgical. Nurs. J, 10(2), 47-51.
\end{abstract}

\section{INTRODUCTION}

Diabetes Mellitus is a degenerative disease, namely a disease due to the function or structure of the body's tissues or organs that progressively declines over time from age or lifestyle choices. (Nuraisyah, 2018). Diabetes Mellitus is a silent killer disease characterized by high blood glucose levels and insulin secretion failure or inadequate use of insulin in metabolism, so to maintain stable blood glucose requires insulin therapy. Insulin therapy often has an impact in the form of hypoglycemia due to inadequate insulin administration which tends to be excessive or even failure of the mechanism due to the longstanding DM disease process.(Fauzi, 2013). Hypoglycemia is an acute complication of diabetes mellitus that can occur repeatedly and can aggravate diabetes mellitus and even cause death(Nuraisyah,
2018).Hypoglycemia occurs due to an increase in insulin in the blood and a decrease in blood glucose levels caused by inadequate insulin therapy (Piette, et al, 2000).

The high prevalence and high risk of severe hypoglycemia are related to the behavior of people with diabetes mellitus in managing their disease, especially the behavior of detecting hypoglycemic episodes. The act of detecting hypoglycemic episodes is a must for a diabetic patient. Factors that influence a person's behavior in controlling diabetes as an early detection effort to increase or decrease blood glucose include the level of knowledge, age, lifestyle and attitude or behavior (Rosland, et al, 2008). This phenomenon triggers the issue of increasing the ability of chronic disease sufferers to manage their disease (self-management) including managing diet, lifestyle, exercise, rest and control the condition of 
the disease so that it can improve the quality of life of chronic disease sufferers and reduce morbidity and mortality due to chronic disease. Issues related to self-management have been raised through several studies. Improved self-management in patients can facilitate patients in making the right decisions related to their condition including controlling the state of the disease, determining when to contact health workers for help and increasing patient awareness of the importance of managing a lifestyle.(Arifin \& Damayanti, 2015). In implementing the self-management program, adjustments need to be made to various aspects including aspects of the system, cost, effectiveness, obstacles and support from related parties. This makes researchers interested in studying further about the optimization of SMBG in patients with diabetes mellitus in hypoglycemic episodes. The purpose of this study is to present the basics of optimizing SMBG in patients with diabetes mellitus in hypoglycemic episodes.

\section{METHOD}

This research is a research in the form of a Literature Review. This research is used to collect data or sources related to the topic from various sources such as journals, books, internet, other bibliography. Researchers conducted searches on various search engines including: Google Scholar, PubMed, .Proquest, Scopus and Science Direct using the keywords, Self Monitoring Blood Glucose, Diabetes Mellitus. Then articles or journals that matched the inclusion and exclusion criteria were taken for further analysis. The inclusion criteria included articles published in 2000-2020, in Indonesian and English, the theme of Self Monitoring Blood Glucose as an act of detecting hypoglycemic episodes, subjects in patients with type $2 \mathrm{DM}$, primary research design: correlation studies and comparative studies.

\section{RESULT}

Description of Self Monitoring Blood Glucose in diabetes mellitus for detection of hypoglycemic episodes. The incidence of hypoglycemia is more common in the elderly (Naibaho \& Kusumaningrum, 2020). Age is strongly associated with susceptibility to the incidence of hypoglycemia and some literature states that age is a risk factor for the incidence of hypoglycemia. Based on the theory, old age will experience changes in energy that will affect the respondent's activities and result in a decrease in quality of life. Unlike the case with young people are still able to carry out daily activities so that the quality of life increases.

Several other studies say that finance and knowledge also play an important role in the implementation of SMBG. Research conducted by (Naibaho \& Kusumaningrum, 2020)stated that one of the obstacles to implementing the SMBG was related to the financing of equipment for diabetic patients. However, this study is not in line with the research of Cox et al (2015) which stated that the reading and interpretation of the glucometer was an obstacle to the implementation of SMBG in diabetic patients.

The longer you suffer from DM, the more the crisis that occurred in the first year has passed with the hope that the patient's physical, psychological, and social conditions are in better condition and can be controlled. Patients who have had diabetes for a longer time will often experience hypoglycemia, so the experience of hypoglycemia is a stimulus for detection. A person who often experiences illness is more likely to behave by paying attention to his symptoms and then seeking help (Notoadmodjo, 2003). Along with increasing knowledge, the ability to detect the occurrence of hypoglycemia will be better. Knowledge is the result of human sensing or the result of knowing someone about an object through the sensing process (eyes, ears, tongue, nose, skin) (Notoatmodjo, 2010). Knowledge is one of the triggering factors for changes in health behavior. This is in line with research (Kueh et al, 2016) which states that the level of knowledge is a strong predictor of behavior and self-care management. Knowledge is one of the predictors of behavior change. According to the Thought and Feeling theory (Notoatmojo, 2010), knowledge can be obtained from own experience or from others. A person's experience in taking care of himself will provide knowledge about how to do this. Individuals who have had diabetes mellitus for longer have been doing self-care along with the course of the disease. Thus the experience that has been gained will be more and more and increase his knowledge. On the other hand,

The limitations of the concept of selfmanagement/ability in detecting the occurrence of hypoglycemia is a very complex matter to be investigated. Factors that affect the ability to detect hypoglycemia are not limited to age, gender, length of illness, level of education and availability of a glucometer. However, there are still many other factors that need to be studied, including depression, family support, self-care behavior. The limitation of this research is that it only looks at the factors of a few elements. In addition, in this study, researchers only 


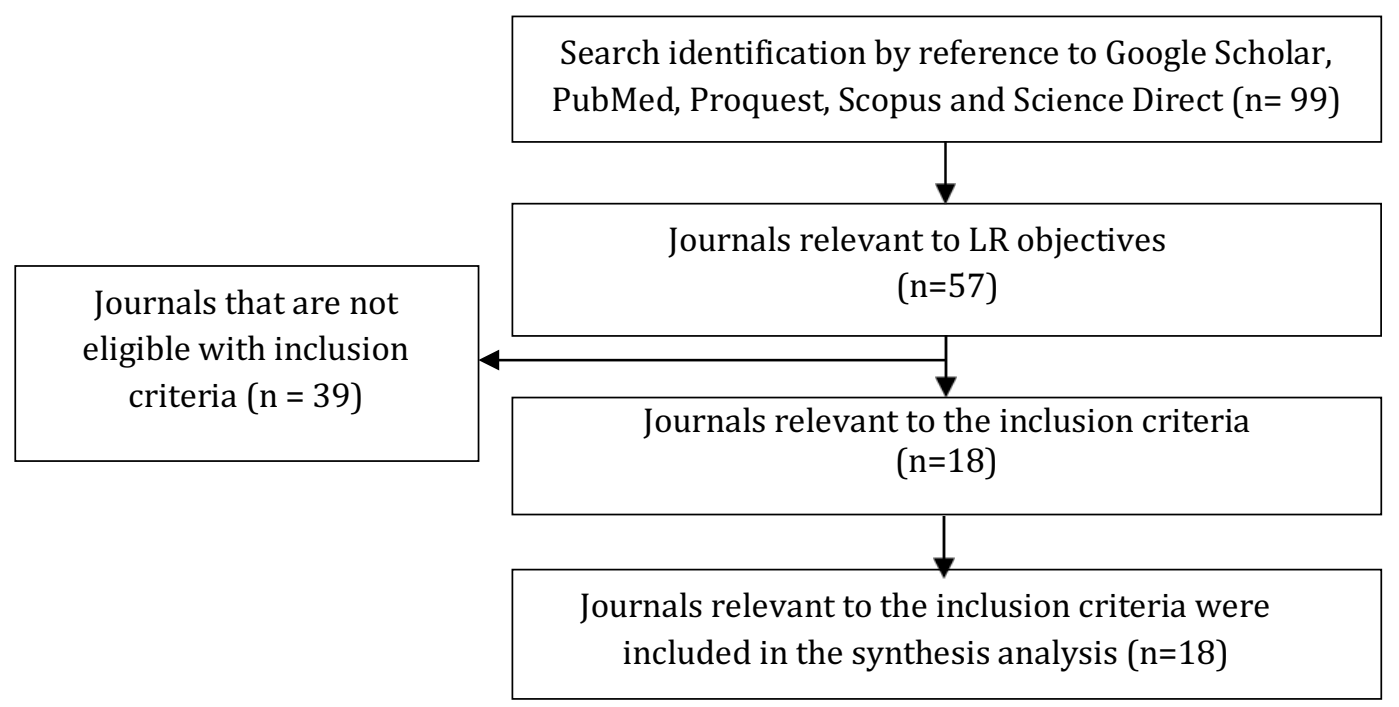

Figure 1. Article Selection Process

assessed the ability to detect hypoglycemia from a questionnaire that only described the frequency of daily implementation.

\section{DISCUSSION}

The optimal management of self-monitoring blood glucose management in diabetic patients has not been established, this is due to other influencing factors such as the level of knowledge, the availability of glucometers, and socio-economic making the scale of clinical trials large and difficult. Many previous studies stated that self-monitoring of blood glucose was successful but was influenced by several factors including level of knowledge, availability of glucometer, socio-economic and long suffering. However, many patients are successful in overcoming hypoglycemic episodes by selfmonitoring blood glucose. The incidence of hypoglycemia is more susceptible to being experienced by the elderly.(Naibaho \& Kusumaningrum, 2020).

Hypoglycemia occurs due to increased insulin levels after insulin administration or consumption of drugs that can affect insulin secretion such as sulfonylureas to increase. The mechanism of hypoglycemia is caused by excessive insulin production due to counterregulatory hormone disturbances and hypoglycemia that the patient is not aware of.(Naibaho \& Kusumaningrum, 2020)This hormone acts as an antagonist to the action of insulin, which lowers blood sugar levels. Disruption of this counterregulatory hormone can cause a 25 times greater risk of hypoglycemia compared to unconsciousness in the hypoglycemic state itself (Poretsky, 2010). Hypoglycemia is established when the blood glucose level is $<70 \mathrm{mg} / \mathrm{dl}$. Signs and symptoms of hypoglycemia include tachycardia, sweating, restlessness, cyanotic skin, drowsiness, confusion, headache and numbness in the fingers, toes and lips.(Hulkower, Pollack, \& Zonszein, 2014; Shoback, 2014).

Experience of exposure to hypoglycemia and history of DM also affect knowledge of the identification and treatment of hypoglycemia. According to Khan, et. al, that knowledge about hypoglycemia can be obtained by diabetic patients from experience (passive learning) experiencing symptoms of hypoglycemia (Khan, et al., 2000). The duration of suffering from DM and the frequency of hypoglycemia experienced by the patient provide an intrinsic experience as a learning process in increasing knowledge. This is in line with behavioral theory that the more often you experience or get a stimulus, the greater the behavioral change (Notoatmodjo, 2013).

The affective domain includes attitudes which are readiness to take action. Detection actions must be supported in addition to adequate knowledge as well as an attitude in the form of the ability to identify and interpret that the symptoms of hypoglycemia they experience are a health problem that must be addressed. DM patients who ignore hypoglycemia or do not consider it a problem to watch out for have a tendency to experience a more severe condition (Sudoyo, 2016). The implication of the action is the behavior of detecting hypoglycemic episodes in the form of routine blood glucose monitoring either done alone or with the help of health workers, using insulin or OHA, regulating diet, activities and self care. The ability to detect hypoglycemic episodes as a behavior is a dominant factor in the success of DM management and disease prognosis. DM patients who have the ability to detect hypoglycemic episodes have a great chance of preventing major complications. 
The ability to perform early detection of hypoglycemic episodes is an important factor that determines the success of diabetes management both in dealing with greater hypoglycemia (Hudak \& Gallo, 2015). The ability to detect hypoglycemic episodes is a behavior that must be possessed by diabetic patients. According to (Notoadmomodjo, 2003) that behavior is a person's response or reaction to a stimulus. The behavior of detecting hypoglycemic episodes includes diabetic control in the form of routine blood glucose monitoring, diet regulation, use of insulin or OHA and physical activity habits (Zrebiec, 2016).

Detection of hypoglycemic episodes is one form of behavior that a person must have in managing diabetes, especially in maintaining blood glucose balance, which in turn can maintain health status. This behavior is related to the efforts or actions of someone who suffers from a disease that begins with self-treatment. or seek help from others. One of the self-management actions that diabetic patients can take to prevent severe hypoglycemia is to independently monitor glucose (Smeltzer, 2018).

In general, a person's behavior is influenced by experience, knowledge, facilities, attitudes, motivation and socio-culture (Naibaho \& Kusumaningrum, 2020)Factors that influence a person's behavior in carrying out diabetes control as an effort to detect an increase or decrease in blood glucose are knowledge, age, lifestyle and attitude or behavior (Pace, et al, 2016). According to the behavioral theory according to Lawrence Green (Notoadmodjo, 2003) individual health behavior consists of 3 aspects, namely, disease prevention behavior, health promotion behavior and nutrition/food drinking behavior. Health behavior is influenced by three factors, namely: 1) predisposing factors ) includes knowledge, attitudes, traditional beliefs, social norms, experiences, and other forms contained in individuals and society. 2) the supporting factors (enabling factors) are the availability of health service facilities and the ease of achieving them,

Diabetes self-management education (DSME) provides information and skills needed by people with T2DM to effectively self-manage their diabetes, in addition to medical management, to achieve optimal glycemic control (Funnell \& Anderson, 2014). Developed countries such as the UK (UK) and the United States (US) have successfully integrated DSME into their health systems, both of which have national guidelines for the provision of DSME (Haas et al., 2012; NICE Internal Clinical Guidelines Team, 2015). In Western culture, DSME is designed with the guiding principles of: (a) effective for improving clinical outcomes and quality of life; (b) it develops from a theory-based model of empowerment; (c) although there is no "best" approach to education, culturally and age-appropriate programs that combine behavioral and psychosocial strategies show better results; (d) ongoing support is essential to sustain progress and; (e) behavioral goal setting is an effective strategy (Funnell et al., 2008). Programs such as diabetes education and self-management for ongoing and newly diagnosed (DESMOND) were associated with improved clinical outcomes (Davies et al., 2008), and the Diabetes Self-Management Program (DSMP) demonstrated improvements in depression, healthy eating habits, patient-to-patient relationships. more effective healthcare providers, communication and self-efficacy (Lorig, Ritter, Villa, \& Armas, 2009) in the UK and the US, respectively. Meanwhile, also in the United States.

\section{CONCLUSION}

Cases of hypoglycemia in patients with diabetes mellitus are very common and can be life-threatening and cause complications. Self-monitoring of blood glucose is effective and is a safe therapy for cases of diabetes mellitus. Self Monitoring Blood Glucose is the best prevention option for diabetes mellitus patients to prevent further complications.

\section{REFERENCE}

Ash, S., Courtney, MD, .. Friedman, RH (2010). Randomised controlled trial of an automated, interactive telephone intervention to improve type 2 diabetes self-management (telephonelinked care diabetes project): Study protocol. BMC Public health, 10, 599.doi:http://dx.doi.org/10.1186/1471-245810-599

Black, J., \& Hawks, JH (2009). Medical Surgical Nursing : Clinical Management for Positive Outcome (8th ed.). St. Louis: ElsevieR

Brady, TJ, Murphy, L., Colmain, BJO, Beauchesne, D.,

Daniels, B., Greenberg, M., ... Chervin, D. (2013). A Meta analysis of health status, health behaviors, and health care utilization outcomes of the chronic disease self management program. Preventing Chronic Disease, 10, 114.https://doi.org/10.5888/pcd10.120112

Castillo, A., Giachello, A., Bates, R., Concha, J.,

Ramirez, V., Sanchez, C., ... Arrom, J. (2010). Community-based Diabetes Education for Latinos: The diabetes empowerment education program. The Diabetes Educator, 36(4),586 594.https://doi.org/10.1177/014572171037152 4

Choi, YJ, Lee, MS, An, SY, Kim, TH, Han, SJ, Chung, YS, Lee, KW \& Kim, DJ, 2011. The Realtionship between Diabetes Mellitus and Health-Related Quality of Life in Korean Adults: The Fourth Korea National Health and Nutrition Examination Survey (2007-2009). DiabetesMetabolism Journal, 35(6), pp. 587-594

Davies, MJ, Heller, S., Skinner, TC, Campbell, MJ, Carey, ME, Cradock, S., ... Khunti, K. (2018). 
Effectiveness of the diabetes education and self management for ongoing and newly diagnosed (DESMOND) program for people with newly diagnosed type 2 diabetes: Cluster randomised controlled trial. BMJ, 336(7649),

Funnell, MM, \& Anderson, RM (2004). Empowerment and self-management of diabetes. Clinical Diabetes, 123127.https://doi.org/10.2337/diaclin.22.3.12 $\underline{3}$

Haas, L., Maryniuk, M., Beck, J., Cox, CE, Duker, P., Edwards, L., ... Youssef, G. (2012). National standards for diabetes self-management education and support. Diabetes Care, 3, 2393 2401.https://doi.org/10.2337/dc12-1707

Hunt, CW, Wilder, B., Steele, MM, Grant, JS, Pryor, ER, \& Moneyham, l. (2012). Relationships Among Self Efficacy, Social Support, Social Problem Solving, and Self Management in a Rural Sample Living with Type 2 Diabetes Mellitus. Research and Theory for Nursing Practice: An International Journal, Vol. 26, No.2, 2012

Kueh, YC, Morris, T., Borkoles, E., \& Shee, H. (2016). Modeling of diabetes knowledge, attitudes, selfmanagement, and quality of life: a cross-sectional study with an Australian sample. Health and Quality of Life Outcomes, 13, 129.http://doi.org/10.1186/s12955-015-0303-8

Notoatmodjo, S. (2010). Health research methodology. Jakarta: PT Rineka Cipta.
Piette, JD, Weinberger, M., McPhee, SJ, Mah, CA, Kraemer, FB, \& Crapo, LM (2000). Do automated calls with nurse follow-up improve self-care and glycemic control among vulnerable patients with diabetes? The American Journal of Medicine, 108, 20-27. doi:10.1016/S0002-9343(99)0029\

Rosland, A., Kieffer, E. Israel, B., Cofield, M., Palmisano, G., Sinco, B., . . .Heisler, M. (2018). When is social support important? the association of family support and professional support with specific diabetes self-management behaviors. Journal of General Internal Medicine, 23(12), 1992-

9.two:http://dx.doi.org/10.1007/s11606- 0080814-7

Shaw, JE, Sicree, RA, \& Zimmet, PZ (2010). Global estimates of the prevalence of diabetes for 2010 and 2030. Diabetes Research and Clinical Practice, 87, 4-14. doi: 10.1016/j.diabres.2009.10.007

Smeltzer, SC, \& Bare, BG (2007). Brunner \& Suddarths's textbook of medical surgical nursing. Philadelphia: Lippincott.

Smeltzer, SC, \& Bare, BG (2018). Brunner \& Suddarths's textbook of medical surgical nursing. Philadelphia: Lippincott. 